\title{
GLOBAL PASSWORD FOR EASE OF USE, CONTROL AND SECURITY
}

\author{
Untung Rahardja ${ }^{1}$ \\ Valent Setiatmi ${ }^{2}$ \\ Dhita Rukmianti ${ }^{3}$
}

untung@pribadiraharja.com,valent@pribadiraharja.com,dhita@pribadiraharja.com

Diterima: 9 April 2010/Disetujui: 25 April 2010

\begin{abstract}
Authentication is applied in irformation systems for maintaining the corfidentiality and data security. Commonly used way is by giving a password. However, the authentication process as it may cause inconvenience for both users and administrators, ie if they are in environments that have many $d_{1 j}$ ferent systems, where in each c f these systems implement an authentication process $d_{i j}$ ferent from one another. Through a global method c f password, a user does not need to enter passwords repeatedly to enter into multiple systems at once. In addition, administrators also do not need to acjust the data in each database system in case a user changes to data. In this article, ident fied problems faced by the company in terms cf authentication using passwords on web-based irformation systems, defined seven characteristics of the concept if a global method of authentication with a password as a troubleshooting step, and determined the bentfits cf implementing these new concepts. In addition, the displayed listing program written using ASP script and its implementation on the Student Ir formation Services (SIS) Online JRS in Higher Education Prog. In the global method (f passwords, not only the security level is concerned, but also convenience and ease both in the process of using both at the time control.
\end{abstract}

Keywords: Global Password, Authentication, Security, Databases, Ir formation Systems

\section{ABSTRAK}

Authentication diterapkan di dalam sistem irformasi untuk merjaga kerahasiaan dan keamanan data. Cara yang umum digunakan adalah melalui pemberian password. Akan tetapi, proses authentication seperti ini justru dapat menimbulkan ketidaknyamanan baik bagi user maupun administrator, yakni apabila berada pada lingkungan yang memiliki

1. Dosen Jurusan Sistem Informasi STMIK Raharja

Jl. Jend. Sudirman No. 40 Cikokol - Tangerang Telp. 5529692

2. Dosen Jurusan Sistem Informasi STMIK Raharja

Jl. Jend. Sudirman No. 40 Cikokol - Tangerang Telp. 5529692

3. Mahasiswa Jurusan Sistem Informasi STMIK Raharja

Jl. Jend. Sudirman No. 40 Cikokol - Tangerang Telp. 5529692 
banyak sistem berbeda, dimana pada masing-masing sistem tersebut menerapkan proses authentication yang berbeda satu sama lain. Melalui metode global password, seorang user tidak harus memasukkan password berulang-ulang untuk masuk ke dalam beberapa sistem sekaligus. Di samping itu, administrator juga tidak perlu menyesuaikan data pada masing-masing database sistem apabila terjadi perubahan terhadap data seorang user. Dalam artikel ini, diidentifikasikan masalah yang dihadapi perusahaan dalam hal authentication menggunakan password pada sistem irformasi berbasis web, did€finisikan 7 ciri khas dari konstp authentication dengan metode global password sebagai langkah pemecahan masalah, dan ditetapkan mar faat dari penerapan konsep baru tersebut. Selain itu, ditampilkan listing program yang ditulis menggunakan script ASP serta implementasinya pada Students Ir formation Services (SIS) Online JRS di Perguruan Tinggi Raharja. Dalam metode global password, tidak hanya level keamanan yang diperhatikan, namun juga kenyamanan dan kemudahan baik dalam proses penggunaan maupun pada saat pengendalian.

Kata kunci: Global Password, Authentication, Keamanan, Database, Sistem In formasi

\section{PENDAHULUAN}

Dalam sebuah sistem, lingkungan luar (environments) memperngaruhi operasi sistem, dan dapat bersifat merugikan atau menguntungkan sistem tersebut. Kemanan eksternal, keamanan internal, serta keamanan interface pemakai merupakan tiga macam keamanan sistem yang dapat digunakan [Miss09]. Keamanan dalam sebuah sistem menjadi hal yang penting mengingat sistem informasi menyediakan informasi yang dibutuhkan oleh organisasi [Jogi00].

Aspek keamanan yang kerap diperhatikan adalah dalam hal interface pemakai, yakni berkaitan dengan identifikasi user sebelum user diijinkan mengakses program dan data yang disimpan. Salah satu komponen utamanya adalah authentication. Tipe authentication yang paling banyak dipakai adalah knowledge based authentication, yakni melalui penggunaan password atau PIN [Chan09].

Pada sistem informasi yang menerapkan authentication menggunakan passsword, setiap user melakukan log in ke dalam sistem dengan mengetikkan username dan password, yang idealnya hanya diketahui oleh sistem dan user yang bersangkutan.

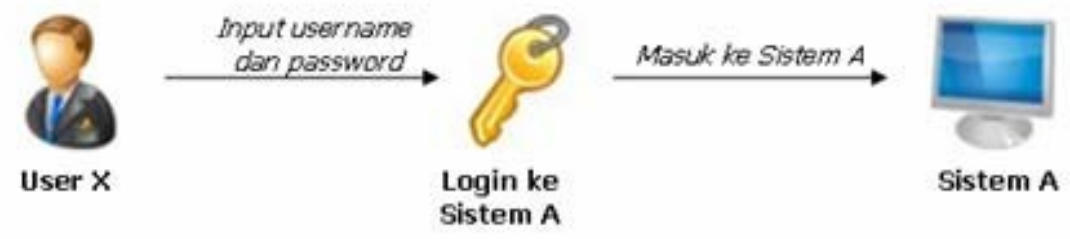

Gambar 1. User melakukan log in ke dalam sebuah sistem

Proses di atas sepintas tidak memiliki masalah. Hal ini karena user tersebut hanya melakukan akses terhadap satu sistem saja. 
Namun, kondisi berbeda akan terasa jika user berada pada lingkungan dimana terdapat lebih dari satu sistem. Apabila setiap sistem memiliki proses authentication sendiri-sendiri, maka dapat menimbulkan ketidaknyamanan dari sisi user yang memiliki banyak akun. Hal tersebut dapat menyulitkan, sebab setiap kali user mengakses sistem berbeda, maka ia harus mengetikkan password tersebut satu per satu untuk masingmasing sistem. Keadaan akan menjadi lebih sulit apabila untuk tiap sistem, user tersebut memiliki username dan password yang berbeda-beda.

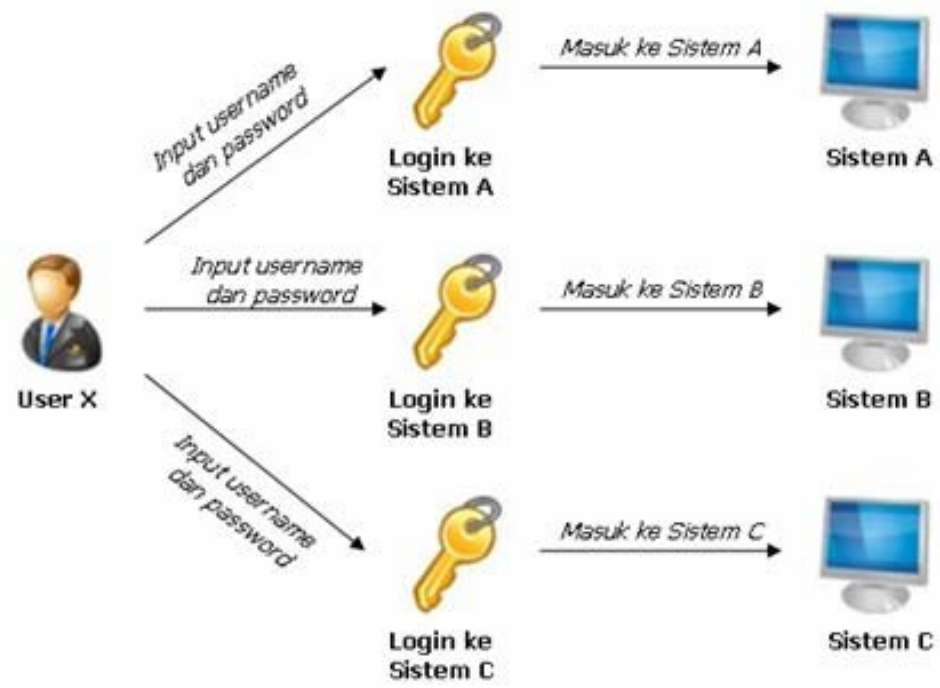

Gambar 2. User melakukan log in ke dalam lebih dari satu sistem

Proses log in merupakan saat dimana sistem diyakinkan bahwa user yang sedang berusaha mengakses adalah benar-benar berhak. Sistem informasi berbasis web biasanya menyimpan data perihal username dan password tersebut pada sebuah tabel di dalam database. Karena itu, sistem akan memeriksa ke dalam database apakah username dan password yang dimasukkan tersebut sesuai atau tidak.
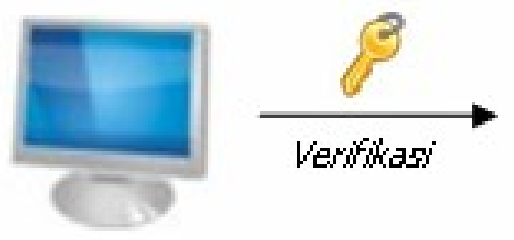

Sistem A

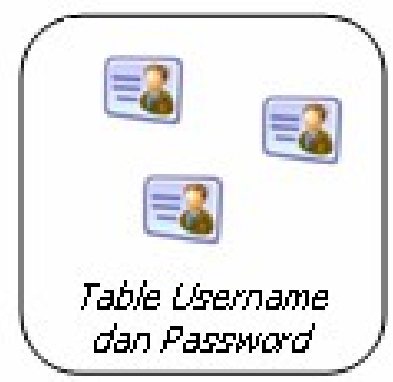

Database Sistem A

Gambar 3. Sebuah sistem memeriksa username dan password user pada database 
Di dalam manajemen sistem informasi, biasanya terdapat administrator yang bertanggung jawab perihal authentication. Administrator harus dapat meyakinkan bahwa data authentication untuk masing-masing user pada sistem tersebut selalu update. Apabila terdapat perubahan user maupun perubahan password, administrator harus siap meng-update data pada database sistem yang bersangkutan.

Kondisi seperti ini akan menjadi rumit bagi lingkungan dengan sistem yang majemuk, yakni apabila tiap sistem memiliki database password masing-masing. Kesulitan terletak pada sinkronisasi data authentication user antara satu sistem dengan sistem lainnya. Terutama apabila terdapat seorang user yang memiliki akun di lebih dari satu sistem.

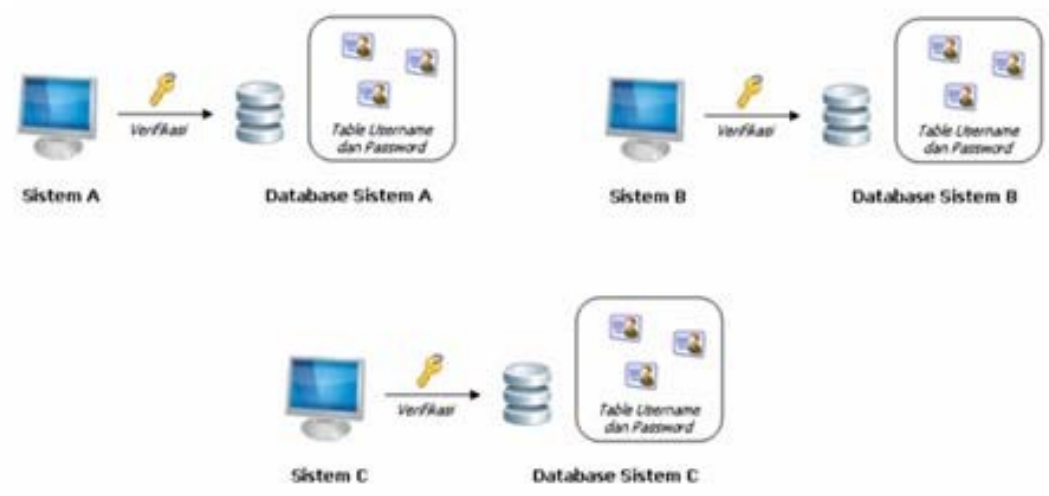

Gambar 4. Tiap sistem memeriksa username dan password user pada databasenya masing-masing

Pada kondisi ini, apabila suatu ketika user tersebut berniat melakukan perubahan password pada seluruh akunnya, maka administrator harus siap melakukan update perihal data password user tersebut pada masing-masing database sistem. Administrator juga harus dapat mengetahui pada sistem mana saja user tersebut memiliki akun. Keadaan seperti ini tentu akan menyulitkan administrator dalam upayanya untuk menjaga agar data authentication user selalu update.

\section{PEMBAHASAN}

\section{Literature Reviewe}

Dan dalam upaya pengembangan global password ini perlu dilakukan studi pustaka sebagai salah satu dari penerapan metode penelitian yang akan dilakukan. Diantaranya adalah mengidentifikasikan kesenjangan (identify gaps), menghindari pembuatan ulang (reinventing the wheel), mengidentifikasikan metode yang pernah dilakukan, meneruskan penelitian sebelumnya, serta mengetahui orang lain yang spesialisasi dan area penelitiannya sama dibidang ini. Beberapa Literature review tersebut adalah sebagai berikut : 
1. Penelitian yang dilakukan oleh Halga Tamici dari Sekolah Teknik Elektro dan Informatika, Institut Teknologi Bandung tahun 2007 berjudul "Analisa Kinerja Cryptography Secure Hash Standard pada Digital Signature Standard". Penelitian ini membahas mengenai Keamanan pada proses transmisi data, salah satunya yaitu pada cryptography. Pada penelitian ini, dijelaskan perihal Cryptography yang merupakan ilmu teknik matematika yang berhubungan dengan aspek keamanan informasi seperti kerahasiaan, integritas data, authentication dan keaslian data. Algoritma cryptography merupakan blok penting yang digunakan untuk memberikan keamanan pada jaringan komunikasi umum, seperti internet. Bersamaan dengan peningkatan pada konektivitas wireless dan data rate, keamanan protokol telah dikembangkan beberapa tahun lalu termasuk algoritma cryptography yang lebih resource-friendly. Terdapat berbagai macam jenis standarisasi cryptography pada FIPS (Federal Information Processing Standards) sesuai dengan fungsinya. Salah satu standar cryptography pada FIPS yang dapat membangkitkan tanda tangan digital adalah Digital Signature Standard (DSS). Pada kebanyakan file-file penting selalu diutamakan informasi identitas user pengirim untuk membuat suatu privasi. Proses ini dilakukan untuk mengubah signature menjadi dokumen digital . Sehingga pada saat pengaksesan dokumen digital tersebut terdapat verifikasi pada siganture yang diberikan.

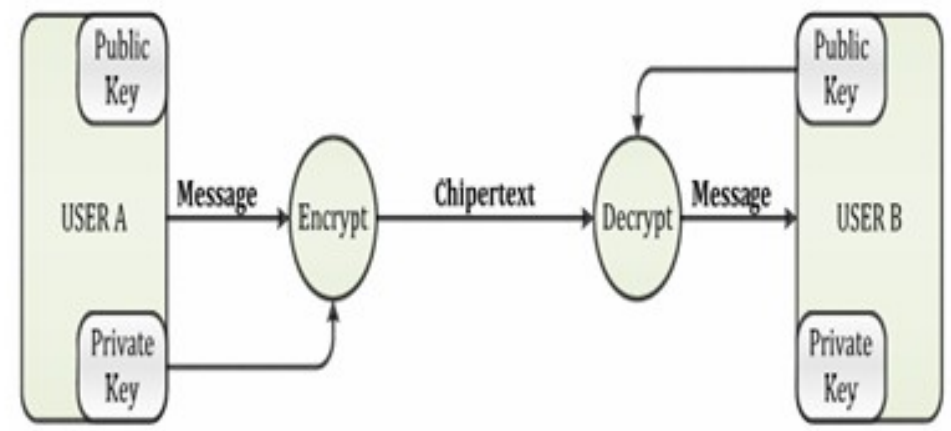

Gambar 5. Proses enkripsi dan dekripsi public-key

2. Penelitian yang dilakukan oleh Kodrat Iman Satoto, R. Rizal Isnanto, dan Ahmad Masykur dari Universitas Diponegoro tahun 2009 berjudul "Analisis Keamanan Sistem Informasi Akademik Berbasis Web Di Fakultas Teknik Universitas Diponegoro". Penelitian ini membahas mengenai Sistem Informasi Akademik berbasis web (web-based SIA) yang telah digunakan oleh seluruh mahasiswa Fakultas Teknik Universitas Diponegoro Semarang, untuk mengetahui seluruh 
catatan akademik mahasiswa yang disimpan melalui jaringan kampus, oleh karena itu maka perlu dilakukan penelitian mengenai keamanan sehingga didapatkan sistem yang aman. Penelitian ini dilakukan dengan langkah-langkah di antaranya analisis dan pengujian sistem terpasang, analisis kebutuhan, perancangan solusi permasalahan, pembuatan modul perbaikan, pemasangan modul dan pengujian ulang modul perbaikan. Dari hasil penelitian yang dilakukan dapat disimpulkan bahwa terdapat kelemahan pada sistem login. Kelemahan tersebut meliputi penggunaan Nomor Induk Mahasiswa (NIM) sebagai nama pengguna dan kata sandi default, data nama pengguna dan kata sandi tidak dienkripsi sebelum dikirim ke server melalui jaringan, jejak nama pengguna dan kata sandi yang tertinggal di peramban sebagai cache atau dalam pengelola kata sandi dapat dilihat sebagai teks sederhana (plaintext) tidak terenkripsi. Dari hasil analisis keamanan tersebut, sistem login SIA dapat diperbaiki dengan penerapan teknologi enkripsi HMAC MD5 dan Challenge Handshake Authentication Protocol (CHAP). Challenge dibangkitkan oleh server secara acak dan digunakan sebagai kunci dalam proses enkripsi HMAC MD5. Dengan penggunaan challenge kata sandi yang dikirim berupa nilai hash akan selalu berbeda pada tiap sesi. Javascript di sisi klien digunakan untuk melakukan enkripsi sehingga data sebelum dikirim ke server sudah dalam keadaan terenkripsi.

3. Penelitian yang dilakukan oleh Indah Kurnia dan Febriliyan Samopa, dari Institut Teknologi Sepuluh Nopember tahun 2005 berjudul "Perancangan dan Pembuatan Server Autentikasi Berbasis xml Pada Sistem Terdistribusi". Penelitian ini membahas mengenai cara kerja server autentikasi yang dilakukan pertama kali dengan mendaftarkan semua atribut, selain itu pendaftaran aplikasi juga harus menyertakan daftar user dan hak aksesnya. Aplikasi klien kemudian mengirimkan data user serta identitas aplikasi ke server autentikasi setiap kali ada user yang meminta login. Sebelum data dikirimkan, data tersebut di enkripsi kemudian diubah ke format $X M L$, Sesampainya di server, data tersebut kemudian diterjemahkan ke bentuk teks kemudian didekripsi menjadi plaintext. Data-data ini digunakan sebagai parameter yang akan divalidasi dengan terlebih dahulu melewati proses port knocking. Apabila validasi port knocking tersebut sukses, maka session khusus akan dibuatkan untuk user tersebut. Kemudian session akan dikembalikan lagi ke aplikasi agar dapat diolah lebih lanjut. Proses yang hampir sama juga berlaku jika user meminta akses terhadap suatu prosedur. Perbedaan terletak pada proses validasi yang melibatkan pemeriksaan terhadap validitas session, hak session, hak akses, parameter dan persyaratan yang bisa dipenuhi. Sedangkan pada proses logoff, batas aktif session diakhiri sehingga user tidak 
bisa lagi melakukan akses. Keberadaan server autentikasi terbukti mampu mempermudah integrasi berbagai macam aplikasi di bawah satu sistem keamanan karena semua data ditransfer berformat $X M L$. Selain itu, kemudahan integrasi juga dibuktikan oleh fleksibilitas server autentikasi dalam mengkoordinasi berbagai aplikasi serta user yang menggunakannya. Di sisi lain, server autentikasi juga berfungsi untuk meningkatkan keamanan sistem yang ditunjukkan dalam bentuk resistensi terhadap pembacaan data plaintext, serangan man in the middle dan penyalahgunaan hak akses.

4. Penelitian yang dilakukan oleh Rudy, Riechie, dan Odi Gunadi, dari Universitas Bina Nusantara berjudul "Integrasi Aplikasi Menggunakan Single Sign On Berbasiskan Lightweight Directory Access Protokol (LDAP) Dalam Portal”. Penelitian ini membahas tentang pengimplementasian metode Single Sign On (SSO) dengan menggunakan Central Authentication Service (CAS) dan Lightweight Data Access Protocol (LDAP) di dalam Web Portal Bina Nusantara. Tujuan utama dari pengimplementasian SSO ini adalah untuk menggabungkan aplikasi yang ada pada binus-access ke dalam sebuah site sehingga terbentuk integrasi aplikasi, khususnya dalam bentuk web yang biasa disebut dengan Web Portal. Dengan adanya Web Portal yang menggunakan metode Single Sign On (SSO) ini, berarti setiap user hanya perlu memiliki satu username, satu password. Dan bila ingin mendapatkan layanan atau fasilitas di Web Portal, user ini hanya perlu login satu kali saja bisa dapat menggunakan semua fasilitas atau layanan aplikasi yang ada di dalam Web Portal tersebut. Hal ini dapat mempermudah user dalam menggunakan aplikasi yang ada. User tidak perlu menghapal banyak account, hanya satu account dan tidak perlu berulang kali login, cukup dengan sekali login. Hal ini juga dapat mempermudah dalam pengorganisasian data user yang ada, sehingga keamanan data user lebih terjamin, karena menggunakan tempat penyimpanan data user yang terpusat. CAS digunakan untuk menangani masalah komunikasi antara aplikasi web yang berbeda, sehingga semua aplikasi dapat diintegrasikan ke dalam sebuah Web Portal. LDAP digunakan sebagai sebuah protokol direktori servis, dimana semua data user disimpan di dalam LDAP.

5. Penelitian yang dilakukan oleh Josua Tarigan, dari Universitas Kristen Petra berjudul "Biometric Security: Alternatif Pengendalian Dalam Sistem Informasi Akuntansi Terkomputerisasi". Penelitian ini membahas mengenai metode pengamanan authentication yang lebih untuk akses user, dijawab dengan adanya teknologi biometric security yang mendapat perhatian yang cukup besar bagi organisasi. Implementasi teknologi biometric security cukup luas dalam sistem informasi akuntansi yaitu sebagai pengendalian pada physical access, virtual 
access, e-commerce applications dan covert surveillance. Dalam mengimplementasikan teknologi biometric, ada tiga tahapan yang harus dilakukan organisasi, yakni strategic planning and budgeting, developing a system reliability plan dan documentation. Tantangan yang akan dihadapi dalam mengembangkan teknologi biometric sebagai pengendalian dalam sistem informasi akuntansi yakni standarisasi, aplikasi teknologi hybrid dan manajemen siklus hidup pada biometric security.

Dari kelima literature review yang ada, semuanya hanya membahas mengenai Authentication, Keamanan, Database, dan Sistem Informasi. Disamping itu juga ada pembahasan mengenai keamanan interface dan tipe authentication yang paling banyak dipakai adalah knowledge based authentication, yakni melalui penggunaan password atau PIN. Namun belum ada yang secara khusus membahas perihal global password. Dapat disimpulkan pula bahwa belum ada peneliti yang secara khusus membahas atau mengatasi masalah bagaimana menjaga kerahasiaan dan keamanan data, cara yang umum digunakan adalah melalui pemberian password. Melalui metode global password, seorang user tidak harus memasukkan password berulang-ulang untuk masuk ke dalam beberapa sistem sekaligus. Di samping itu, administrator juga tidak perlu menyesuaikan data pada masing-masing database sistem apabila terjadi perubahan terhadap data seorang user.

\section{Pemecahan Masalah}

Untuk mengatasi permasalahan seperti yang telah dijelaskan di atas, dapat dilakukan melalui penerapan metode Global Password. Berikut merupakan 6 ciri khas dari Global Password yang diterapkan pada proses authentication dalam sistem informasi:

1. Masing-masing user hanya memiliki satu buah username dan password

2. Username dan password user untuk masing-masing sistem adalah sama

3. User hanya cukup melakukan log in satu kali untuk dapat masuk ke lebih dari satu sistem

4. Data authentication user untuk seluruh sistem disimpan dalam satu database yang sama

5. Terdapat level otorisasi

6. Penyesuaian session user pada masing-masing sistem

7. Data password user yang tersimpan pada database telah dienkripsi 
Masalah ketidaknyamanan user dalam hal penginputan username dan password yang berulang-ulang diatasi dengan cara penyederhanaan proses authentication. Berdasarkan ciri Global Password pada poin nomor 3 (tiga), seorang user hanya cukup melakukannya satu kali, yakni pada saat user tersebut melakukan log in awal ke dalam sistem.

Setelah user melakukan log in di awal, dan ia dinyatakan berhak, maka user yang bersangkutan dapat langsung masuk ke beberapa sistem yang diinginkan tanpa harus menginputkan username dan password lagi. Dengan catatan, user tersebut memang memiliki akun pada sistem-sistem yang akan ia akses.

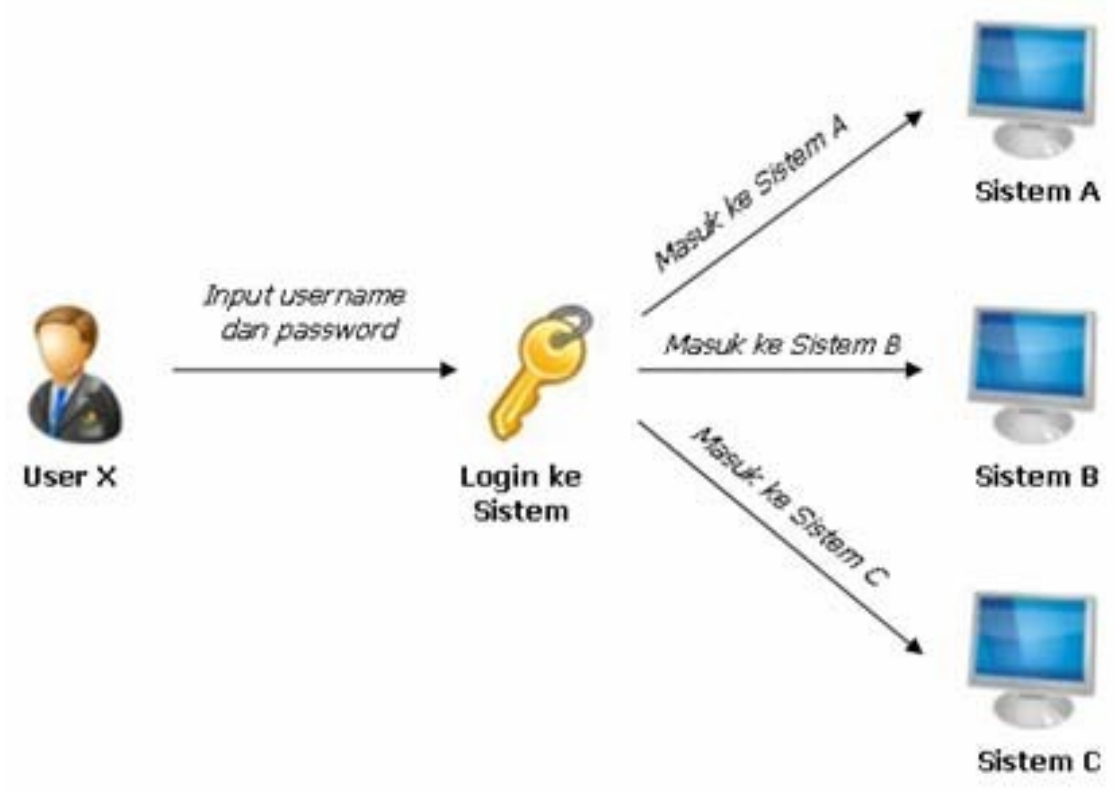

Gambar 6. User hanya cukup log in satu kali di awal

Hal ini dapat dilakukan berkaitan dengan dua ciri Global Password lainnya, yaitu pada poin nomor 1 (satu) dan 2 (dua). Untuk satu orang user, hanya diberikan sebuah username dan password, yang mana dapat digunakan untuk seluruh sistem sekaligus. Adanya penyeragaman username dan password inilah yang memungkinkan untuk dilakukannya komunikasi antar sistem dalam hal verifikasi data. Agar user dapat berpindah dari satu sistem ke sistem lain tanpa melakukan log in, maka pada tiap sistem juga harus dapat membaca session satu sama lain dan menyesuaikannya pada sistem masing-masing. Kondisi ini sesuai dengan ciri Global Password pada poin nomor 6 (enam)

Untuk memudahkan administrator di dalam melakukan pengendalian data authentication user, dilakukan dengan cara penyimpanan data perihal username dan password pada satu tempat yang sama. Sesuai dengan ciri Global Password 
pada poin nomor 4 (empat), data tersebut disimpan dalam sebuah tabel di dalam database tunggal yang digunakan secara bersama-sama oleh seluruh sistem yang terkait.

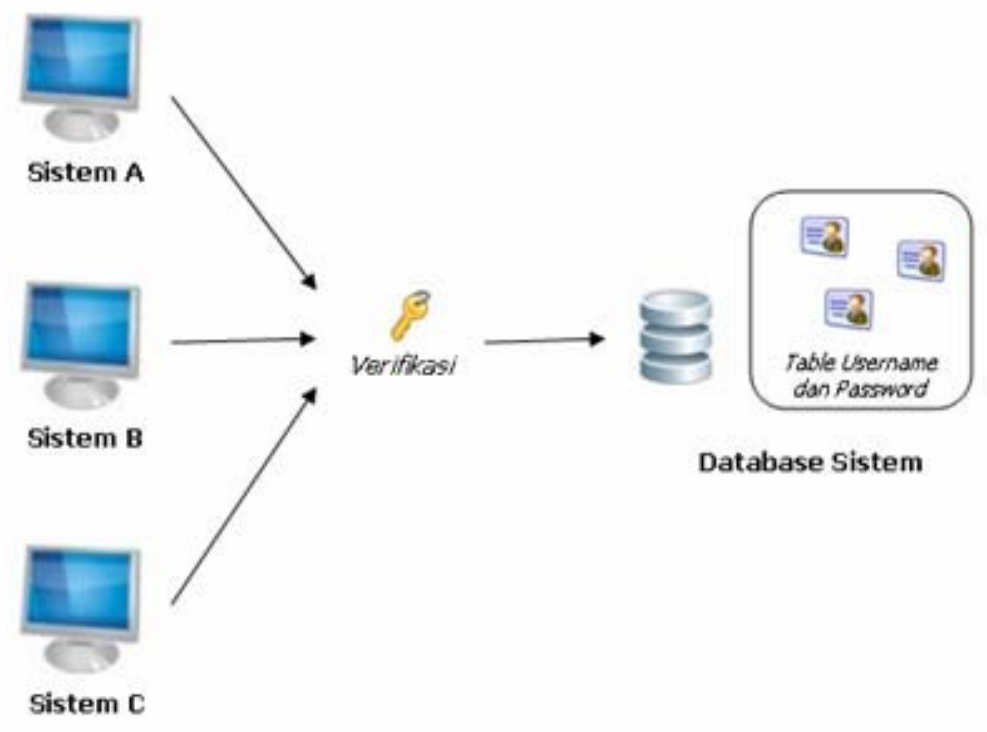

Gambar 7. Data username dan password user untuk masing-masing sistem tersimpan dalam satu database yang sama

Kondisi ini akan memudahkan administrator di dalam melakukan pengendalian data authentication user, karena ia tidak harus melakukan update di beberapa database sistem yang berbeda untuk satu user yang sama.

Di samping itu, pada ciri Global Password poin nomor 5 (lima), metode ini juga mendukung diterapkannya level otorisasi user. Di dalam tabel penyimpanan username dan password, dapat dibedakan level otorisasi masing-masing user berdasarkan klasifikasi data yang tersimpan, sesuai dengan keinginan dan kebutuhan organisasi.

Dari segi keamanan, Global Password juga dilengkapi oleh proses enkripsi. Sesuai karakteristik Global Password point nomor 7 (tujuh), bahwa password masingmasing user yang tersimpan sudah dalam bentuk enkripsi, sehingga tidak mudah diketahui secara kasat mata oleh orang lain.

\section{Implementasi}

Authentication menggunakan metode Global Password sudah diimplementasikan pada Perguruan Tinggi Raharja, yakni pada sistem informasi SIS OJRS (Online JRS). Students Information Services, atau yang biasa disingkat SIS, merupakan sistem yang dikembangkan oleh Perguruan Tinggi Raharja untuk tujuan 
sebagai sistem pelayanan informasi mahasiswa yang optimal [Untu07]. Pengembangan SIS juga merupakan akses publikasi bagi Perguruan Tinggi Raharja di bidang ilmu komputer dan dunia IT khususnya [Untu07].

SIS sudah dikembangkan ke dalam beberapa versi, dimana masing-masing merupakan kelanjutan dari SIS versi sebelumnya. SIS OJRS (Online Jadwal Rencana Studi) merupakan versi SIS yang ke-4. Sesuai namanya, SIS OJRS dibuat untuk kebutuhan perkuliahan mahasiswa, yaitu untuk menyiapkan JRS (Jadwal Rencana Studi) dan KRS (Kartu Rencana Studi) mahasiswa.

Pada SIS OJRS terdapat subsistem-subsistem lainnya, yakni ADM RPU, ADM Dosen, Akademik, GO, Pool Registrasi, Assignment, dan Data Mining. Masingmasing subsistem tersebut berhubungan dengan satu atau lebih bagian di Perguruan Tinggi Raharja. Karena itulah, untuk memudahkan user dalam mengakses atau berpindah antar subsistem diterapkan konsep Global Password. Sebab, tidak jarang user mempunyai akun di lebih dari satu subsistem dan harus berpindah dari subsistem satu ke subsistem lainnya.

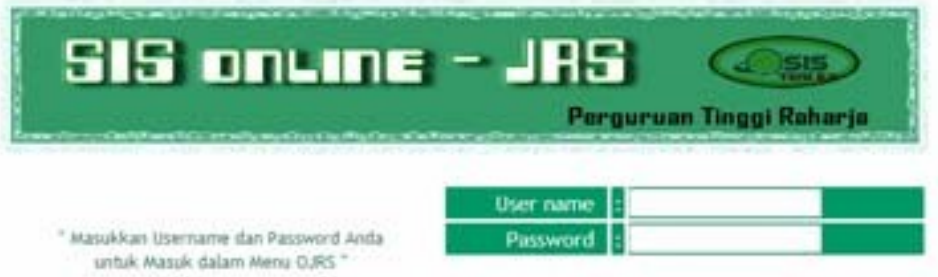

LDEIN
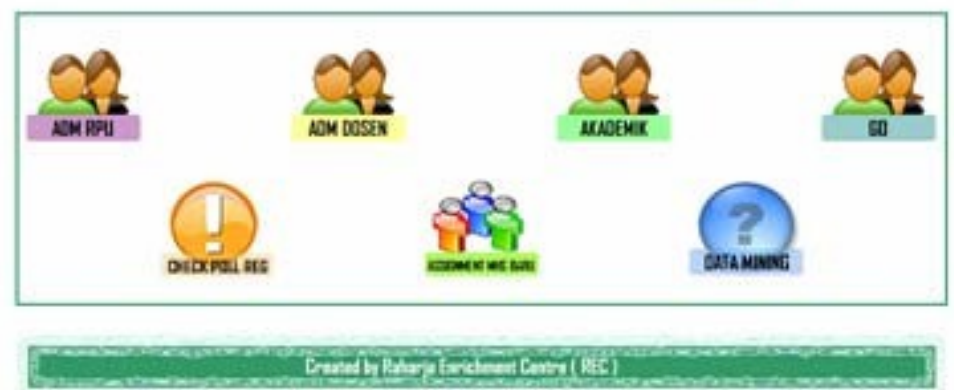

Gambar 8. Halaman log in awal untuk authentication pada SIS OJRS

Gambar di atas merupakan tampilan layar ketika user pertama kali akan masuk dan mengakses SIS OJRS. Pada halaman tersebut, user harus mengetikkan username dan password untuk authentication. Sistem kemudian akan memeriksa data authentication tersebut. Apabila dinyatakan sah, maka user dapat langsung mengakses subsistem-subsistem yang ada di dalam SIS OJRS tersebut tanpa perlu mengetikkan username dan password lagi, tentu saja sesuai dengan level otorisasi yang diberikan kepada user yang bersangkutan. 


\section{a.Database}

SIS OJRS yang diimplementasikan pada Perguruan Tinggi Raharja menggunakan database SQL Server. Di dalam database server tersebut, selain database-database yang digunakan oleh sistem, juga disediakan sebuah database khusus sebagai master untuk menyimpan seluruh data username dan password user. Database tersebut terintegrasi dengan seluruh sistem lainnya, termasuk dengan versiversi SIS sebelumnya.

Pada database inilah dibuat tabel-tabel yang dibutuhkan berkenaan dengan proses authentication. Terdapat dua macam tabel yang harus disiapkan, yaitu: tabel yang berisi data authentication, dan tabel keterangan level otorisasi.

\begin{tabular}{|c|c|c|}
\hline Column Name & Data Type & Allow Nulls \\
\hline Nama & $\operatorname{varchar}(50)$ & $\sqrt{\nabla}$ \\
\hline Username & $\operatorname{varchar}(20)$ & $\sqrt{\nabla}$ \\
\hline Password & varchar(20) & $\sqrt{\nabla}$ \\
\hline Jabatan & nvarchar(20) & ॠ \\
\hline IP_Address & nvarchar(20) & $\sqrt{\nabla}$ \\
\hline OJRS_All & smallint & 『 \\
\hline OJRS_RPU & smallint & 『 \\
\hline OJRS_ADM_Dosen & smallint & $\sqrt{\nabla}$ \\
\hline OJRS_Akademik & smallint & $\sqrt{V}$ \\
\hline OJRS_PoolReg & smallint & $\sqrt{v}$ \\
\hline OJRS_Assignment & smallint & 『 \\
\hline OJRS_DataMining & smallint & $\sqrt{\nabla}$ \\
\hline
\end{tabular}

Gambar 9. Struktur tabel Tb1_Password

Tabel di atas merupakan tabel utama yang merupakan tempat penyimpanan data yang diperlukan untuk authentication. Field-field yang dibutuhkan disesuaikan dengan sistem yang ada. Field Nama, Username, Password, Jabatan, dan IP_Address merupakan field yang menjelaskan data diri user. Sedangkan field-field berikutnya berfungsi sebagai level otorisasi saat user masuk ke masing-masing subsistem.

Isi daripada field password haruslah dalam bentuk yang sudah dienkripsi. Hal ini diterapkan agar password tidak mudah ditebak oleh orang lain, mengingat pada metode ini satu password dapat digunakan untuk masuk ke banyak sistem sekaligus. Adapun bentuk enkripsi yang dimaksud dapat bermacam-macam, disesuaikan dengan kebutuhan organisasi. Dapat hanya berupa angka saja, atau gabungan dari angka, huruf, dan karakter lain. 
Khusus untuk field seperti OJRS_All, OJRS_RPU, OJRS_ADM_Dosen dan sebagainya, dibuat dengan tipe data smallint. Hal ini karena isi daripada fieldfield tersebut hanya berupa angka. Nilai untuk masing-masing angka tersebut mewakili level otorisasi yang diberikan terhadap user yang bersangkutan.

\begin{tabular}{|l|l|l|l|l|l|}
\hline Nama & Username & Jabatan & OJRS_All & OJRS_RPU & OJRS_ADM_Dosen \\
\hline Ir. Untung Rahardja, M.T.I & Rahardja & Pimpinan & 1 & 1 & 1 \\
\hline Valent Setiatmi, S. Kom & Valent & Kasubag REC & 1 & 2 & 2 \\
\hline Hidayati, A. Md & Hida & Staf REC & 1 & 2 & 2 \\
\hline Sity Aisyah Nasution, S. Kom & Aisyah & Kabag RPU & 1 & 1 & NUUI \\
\hline
\end{tabular}

Gambar 10. Isi tabel Tbl Password

Untuk menjelaskan nilai angka yang dimaksud, maka dibutuhkan tabel-tabel lainnya, yang berfungsi sebagai keterangan untuk setiap field pada tabel utama.

\begin{tabular}{|l|l|c|}
\multicolumn{1}{|c|}{ Column Name } & \multicolumn{1}{c|}{ Data Type } & Allow Nulls \\
\hline Nilai & smallint & 『 \\
\hline Keterangan & varchar(50) & 『 \\
\hline
\end{tabular}

Gambar 11. Struktur tabel Tbl OJRS RPU

Isi daripada tabel-tabel tersebut menjelaskan arti dari setiap angka yang dimasukkan pada tabel utama, yakni menyangkut level otorisasi user. Apakah user hanya bisa membaca (read) sistem, melakukan perubahan terhadap data yang tersimpan (update), atau tidak memiliki hak sama sekali (null).

\begin{tabular}{|l|l|}
\hline Nilai & Keterangan \\
\hline 1 & update \\
\hline 2 & read \\
\hline
\end{tabular}

Gambar 12. Isi tabel Tbl_OJRS_RPU

\section{b.Listing Program}

Dengan menggunakan Global Password, proses verifikasi melalui penginputan username dan password hanya dilakukan satu kali. Untuk lebih menjaga keamanan sistem, password yang dimasukkan terlebih dahulu akan dienkripsi. Metode enkripsi tidak dibatasi, disesuaikan dengan kebutuhan. Selain itu, pemeriksaan $I P$ 
Address juga dapat ditambahkan pada saat verifikasi. Berikut adalah potongan script ASP yang digunakan pada saat user log in.

set record = server.createobject("ADODB.Recordset")

record.open "Tbl_Password",conn,3,3

record.filter = "Username = "“\&uname\&" and Password= "“\&pword\&" and IP_Address="'\&ip\&"”,

if not record.eof then

session("a")=record.fields("Username").value response.redirect "default1.asp"

else

response.redirect "default.asp"

end if

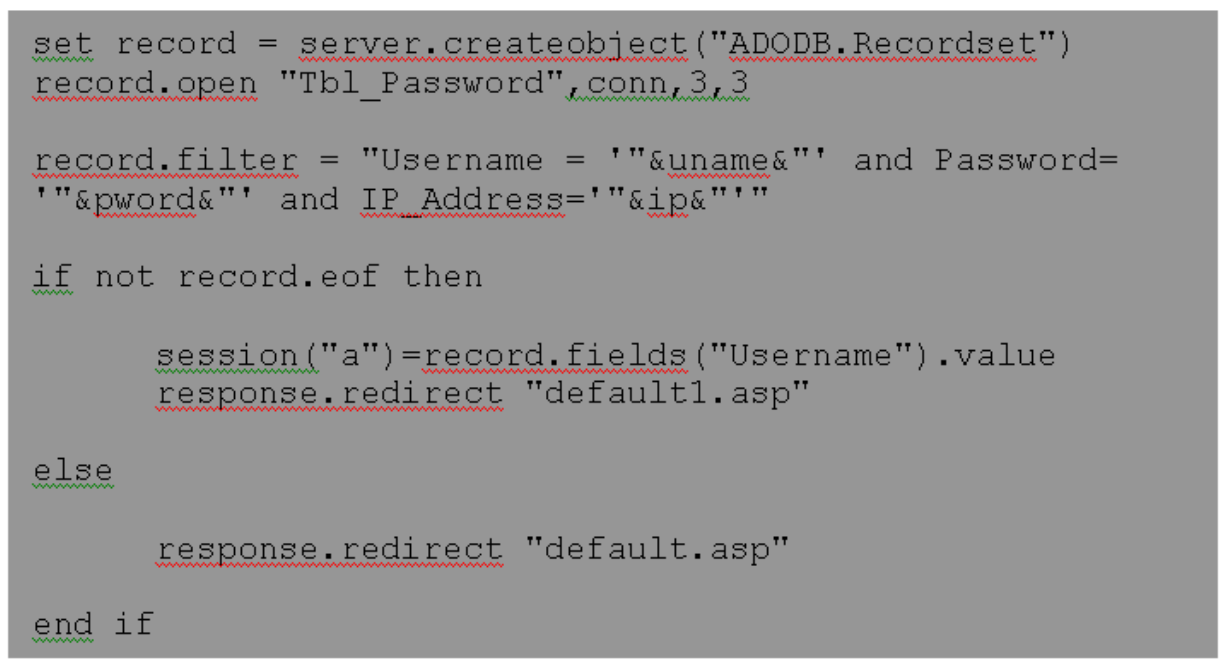

Gambar 13. Potongan script saat user log in

Apabila setelah $\log$ in kemudian user dinyatakan berhak untuk masuk ke dalam sistem, maka akan dibentuk sebuah session. Session inilah yang nantinya digunakan dan dibaca oleh sistem-sistem yang ada di dalamnya sebagai patokan untuk 
kemudian ditentukan apakah user tersebut berhak untuk masuk ke dalam sistem lainnya atau tidak.

Berikut adalah potongan script ASP yang digunakan saat seorang user yang telah berhasil log in pada SIS OJRS lalu ingin mengakses sistem lain yang ada di dalamnya, dalam hal ini adalah ADM RPU:

$\mathrm{b}=\operatorname{session}(" \mathrm{a}$ ")

sql="select OJRS_RPU from Tbl_Password where Username $=$ "“\&b\&"”, set $\mathrm{rs}=$ conn.execute(sql)

if not isnull(rs(“OJRS_RPU”)) then

if rs("OJRS_RPU")=1 then

hak="update data"

response.redirect(“default1.asp")

else

hak="read data"

response.redirect(“default2.asp”)

end if

else

end if

$$
\text { response.redirect(“../default1.asp”) }
$$

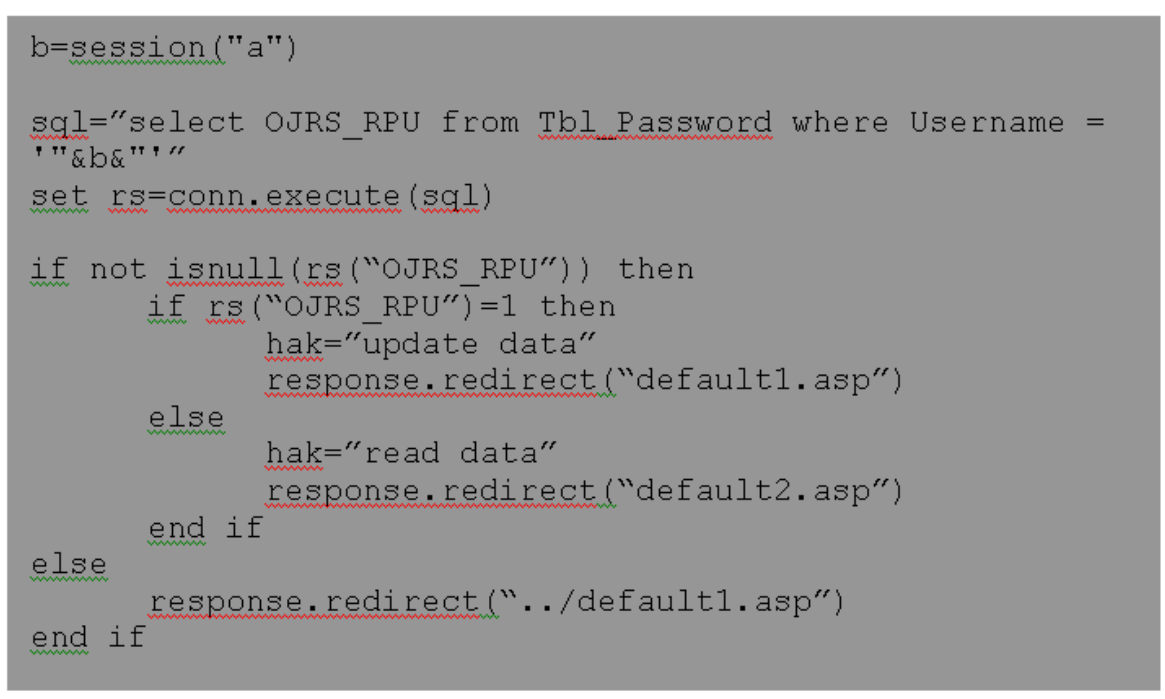

Pada script inilah level otorisasi user diperiksa. Apabila user tidak memiliki hak terhadap sistem tersebut, maka otomatis user tidak dapat masuk ke dalamnya. Peletakkan script yang sesuai menjadi kunci di dalam keamanan sistem. Dalam hal 
ini, pemeriksaan jati diri dan level otorisasi user harus bedara di bagian paling atas, atau setiap kali user hendak masuk ke dalam masing-masing sistem.

\section{SIMPULAN}

Authentication merupakan salah satu bagian penting pada keamanan sistem. Akan menjadi optimal apabila juga memperhatikan kondisi lingkungan dan kebutuhan, baik user maupun administrator. Global Password merupakan konsep baru yang mengakomodir kebutuhan user akan kenyamanan dalam mengakses sistem informasi, khususnya pada lingkungan dengan kondisi sistem yang majemuk. Dari sisi administrator, juga akan menjadi lebih mudah dalam hal pengendalian data authentication untuk masing-masing sistem. Di samping itu, Global Password tetap menjaga kerahasiaan data di dalam sistem untuk tujuan awal, yaitu keamanan sistem informasi.

\section{PUSTAKA}

1. Chandra Adhi W (2009). Identification and Authentication: Technology and Implementation Issues. Ringkasan Makalah. Diakses pada 4 Mei 2009 dari: http:/ /bebas.vlsm.org/v06/Kuliah/Seminar-MIS/2008/254/254-08-Identification and Authentication.pdf

2. Jogiyanto Hartono (2000). Pengenalan Komputer: Dasar Ilmu Komputer, Pemrograman, Sistem Informasi dan Intelegensi Buatan. Edisi ketiga. Yogyakarta: Andi.

3. Missa Lamsani (2009). Sistem Operasi Komputer: Keamanan Sistem. Diakses pada 5 Mei 2009 dari: http://missa.staff.gunadarma.ac.id/Downloads/files/6758/ BAB8.pdf

4. Halga Tamici (2007). Analisa Kinerja Cryptography Secure Hash Standard pada Digital Signature Standard. Sekolah Teknik Elektro dan Informatika, Institut Teknologi Bandung. Ringkasan Makalah Diakses pada 5 maret 2010 dari : http://www.cert.or.id/ budi/courses/security/2007/Halga\%20Proposal.pdf

5. Kodrat Iman Satoto, R. Rizal Isnanto, dan Ahmad Masykur (2009). Analisis Keamanan Sistem Informasi Akademik Berbasis Web Di Fakultas Teknik Universitas Diponegoro. Universitas Diponegoro. Ringkasan Makalah Diakses pada 5 maret 2010 dari : http://eprints.undip.ac.id/5501/1/ Analisis_Keamanan_Sistem_Informasi_Akademik_Babasis_Web_di_Fakullas_Teknik_Univessias_Diponegoropdf

6. Indah Kurnia dan Febriliyan Samopa (2005). Perancangan dan Pembuatan Server Autentikasi Berbasis xml Pada Sistem Terdistribusi. Institut Teknologi Sepuluh Nopember. Ringkasan Makalah Diakses pada 5 maret 2010 dari : http:/ /www.si.its.ac.id/Penelitian/JURNAL/Indah.pdf 
7. Rudy, Riechie, dan Odi Gunadi. INTEGRASI APLIKASI MENGGUNAKAN SINGLE SIGN ON BERBASISKAN LIGHTWEIGHT DIRECTORY ACCESS PROTOCOL (LDAP) DALAM PORTAL..Universitas Bina Nusantara. Ringkasan Makalah Diakses pada 5 maret 2010 dari : http://ict.binus.edu/file/research/jurnalskripsi-odie-v-2.1-revis-renan-RECEIVED.pdf

8. Untung Rahardja (2007). Pengembangan Students Information Services di Lingkungan Perguruan Tinggi Raharja. Laporan Pertanggung Jawaban. Tangerang: Perguruan Tinggi Raharja.

9. Untung Rahardja, Henderi, dan Djoko Soetarno (2007). SIS: Otomatisasi Pelayanan Akademik Kepada Mahasiswa Studi Kasus di Perguruan Tinggi Raharja. Jurnal Cyber Raharja. Edisi 7 Th IV/April. Tangerang: Perguruan Tinggi Raharja. 